\title{
THE DEVELOPMENT PERCEIVED OF PRODUCT COMMENTS TRUST-ABILITY ON SOCIAL MEDIA: A SOCIAL INFORMATION PROCESSING (SIP) THEORY APPROACH (SURVEY ON FACEBOOK COMMUNITY OF TAIWANESE STUDENTS COLLEGES)
}

\author{
Azizah Nurul $^{1 *}$, Suyadi Imam ${ }^{2}$, Kusumawati Andriani $^{1}$ \\ ${ }^{1}$ University of Brawijaya, Indonesia \\ ${ }^{2}$ National Central University, Taiwan \\ *E-mail: nurul.azizah074@gmail.com
}

\begin{abstract}
Web 2.0 based social media, such as Facebook, Twitter, et cetera, has become a popular platform for consumers to look for required information. In the current social media era, the ease of the access of the internet has promoted the utilization of WOM through social media, which is titled social WOM (sWOM hereinafter) in the current study. As a consequence, sWOM has become a prevalent tool for practitioners to take it as an effective marketing tool. However, the ease of interactive nature of social media which differs from the physical may make the effective ways of applying WOM for marketing promotion purposes in virtual environments inapplicable. In the current research, an attempt is therefore conducted to explore the predicting variables of the perceived trust-ability on social media. The two of variables related to social information processing are drawn and hypothesized to affect the perceived product comment trust-ability on social media through comment involvement as a mediator. The scales are adapted from prior literature and a back-translation technique is used to compose the questionnaire. Data are then collected in either private and national university while PLS is used to analyze the collected data. The theoretical and managerial implications are discussed while future research directions are outlined as well. The current research is one of the pioneer works in the ways applying the theoretical concept in sWOM to development the perceived product comment trust-ability on social media.
\end{abstract}

\section{KEY WORDS}

Product Comment Trust-Ability, sWOM, Social Information Processing (SIP) Theory.

Web 2.0 based social media allows users to utilize the web more personally (Kaplan and Haenlein, 2010) and able to interact such as sharing, commenting, and connecting (Katrin, 2015) with their social media communities in an immediate fashion. These unique characteristics have attracted numerous surfers to access social media. According to Jeff (2015), nearly $70 \%$ out of the 3 billion active Internet users have social media accounts while more than 95\% marketers are reported to have participated in social media marketing (Michael, 2015). However, most social media users ignore social media advertisement and more than $45 \%$ consumers have experienced badly on social media marketing (Augie, 2014). In the Web 2.0 based social media era, consumers prefer seeking information from word of mouth rooted on social media, i.e., social WOM (sWOM hereinafter), rather than from a firm's website (Hajli, 2013). Therefore, an alternative solution to improve poor social media marketing performance can be to engage consumers through sWOM (Kaplan and Heinlein 2010). sWOM is regarded as an useful instrument to develop, create and strengthen the relationship with customers, and thus has been prevalently applied in recent years (Chow, 2015). The availability and widespread of sWOM in recent years (Hajli, 2013) have changed the focus of consumers in dealing with the comments in sWOM from presenting comments, to evaluating comments, and then nowadays utilizing comments in social media (Zhiming 2014). Product comments on social media, one type of sWOM, are considered the most effective and helpful social media marketing tool (c.f., Park and Lee, 2008; Cheung and Thadani, 2010). The perceived trust-ability essences play a significant role in arousing consumers' purchase intention and leading to their final decision making (Park and Lee, 
2008). Insight into the driving forces of perceived trust-ability of sWOM, product comments is thus essential in the application of social media marketing.

The Social Information Processing (SIP hereinafter) theory is an interpersonal, relational communication theory applied in the Computer Mediated Communication (CMC) environment (Walther and Burgoon, 1992). Its applicability has been evidenced in various settings, such as customer-focused voice in hospitals (Lam and Mayer, 2014), organizational employee trust ( $\mathrm{Ng}$ and Feldman, 2013), and online dating (Farrer and Gavin, 2009), through various combinations of the SIP theoretical concept. The current research therefore mainly borrows the SIP concept as the fundamental theoretical ground to develop a three-stage framework in which determinants drive the perception of sWOM product comments through an intervening mechanism, thus achieving and enhancing the effectiveness of social marketing. By doing so, the current research contributes to the validation of the applicability of the SIP theory on sWOM. A framework driven by SIP and derived from the interactive, relational communication perspective in dealing with the effectiveness of sWOM product comments is developed and tested. New insight is thus gained and a set of immediate guidance with empirical verification for social media marketers is thus drawn and provided. The rest of this research is organized as follows. Literature is reviewed, hypotheses are developed, and the conceptual framework is formulated. Then, research methodology is presented, followed by data analysis. The current research concludes with a summary of the study, a discussion of the theoretical and managerial implications, and potential avenues for future research.

\section{LITERATURE REVIEW}

The SIP theory (Walther, 1992) is an inter-personal communication theory used in the CMC environment. The theory describes how people meet and develop online relations (Utz, 2000). According to the SIP theory, in online communication despite the unavailability of nonverbal vocal and physical cues, the relationships are expected to approach face-to-face levels over time (Walther and Burgoon, 1992). With time, it is also evidenced that online communicators are able to generate, transmit, and manage interpersonal impressions to signal affective information (See among others, Lam and Mayer 2014; Ramirez et al., 2007; Walther and Burgoon, 1992). The theory suggests that even in an online environment, communication does progress from non-intimate to intimate areas. Contrarily, the SIP theory postulates that when motivated to develop relationships, even though online communicators are unable to provide verbal cues at their disposal, they adapt to the restrictions of the medium by looking for cues and by adapting their social expressions. Thus, relationship development takes place through language context only (Walter, 1992). The underlying assumption in SIP, based on the study of human communication, is that once gaining information about each other, communicators deploy the information to form impressions and eventually develop interpersonal knowledge and stable relations (Walther, 2012).

\section{CONCEPTUAL FRAMEWORK AND HYPOTHESIS DEVELOPMENT}

Intimacy, dominance and comment involvement. In an interactive social media environment, it is easier for participating members to self-disclose their personal information such as their feelings, cognition and mental states, and to exchange interpersonal opinions regarding this information (Tidwell and Walther, 2002). Through non-verbal text mode, the interactive environment also allows relational communication in a timely way (Walther, 2012), as such making the interaction faster compared to traditional environments (Walther, 1997). The characteristics of intimacy that self-disclose, the partner on social media community more likely to get involve in their comment activity (Chu, 2011). Therefore, we propose the hypotheses as below:

$\mathrm{H} 1$ : The higher the perceived intimacy of social media community participants is, the higher the product comment involvement will be. 
Dominance is the degree of ability a person influences or controls the behavior of another person (Perez et al, 2009; Watanabe, 2015). The messages and cues of influence and control, while through verbal, nonverbal or in CMC normally in texts, imply some elements such as comments, persuasion, aggressiveness, ingratiation, and competitiveness (Burgoon and Hale, 1987; Guerrero et al., 2013; Walther and Burgoon, 1992). The public opinions on social media, which along with supporting evidence, are more trustable, believable, competitive, and persuasive, and thus are more dominant (cf., Walther, 2012). More valuable and quality implications of these public opinions are sensed and messaged. The matter of dominance that more valuable and quality will perceive as the persuasive, which drive the engagement of social media community significantly (Lee, 2014). Based on the above-deduced logic, the second hypotheses is developed as follows:

$\mathrm{H} 2$ : The higher the perceived dominance orientation of the participation behavior on social media is, the higher the comment involvement of participation on social media will be.

Comment involvement and product comment trust-ability. Comment involvement for the current study adopted by personal involvement. Generally, involvement was defined as the motivational construct which influenced by the antecedent factor of the person's values and needs (Zaichkowsky, 1994). Hanna (2015) stated personal involvement is one of the important factors to explain consumer behavior. According to Zaichkowsky (1985), personal involvement is a perceive of the person regarding the inherent needs, value, and interest of advertisement (Zaichkowsky, 1994), this definition cover affective and cognitive relevance. Where, effective involvement emphasize to the feeling and achievement of the person while cognitive stresses the informational processing activities individually (Zaichkowsky, 1994). The previous study state that involvement activity explains the extent of sensitivity of the person toward the attribute of activities (Racherla, 2012). The degree of involvement has an impact on the responses to external/product stimulation (Racherla, 2012). Therefore, the higher involvement tends to require more information (Racherla, 2012), then the information content will perceive more trustable. Supported social media as the tool that allowed the user has interaction immediately (Wei Shao, 2015), then it does not matter whether the conversation directly or indirectly. Thus, the third hypothesis is conducted as follow:

H3: The higher the involvement social media is perceived, the higher the perceived trustable the product comment on social media will be.

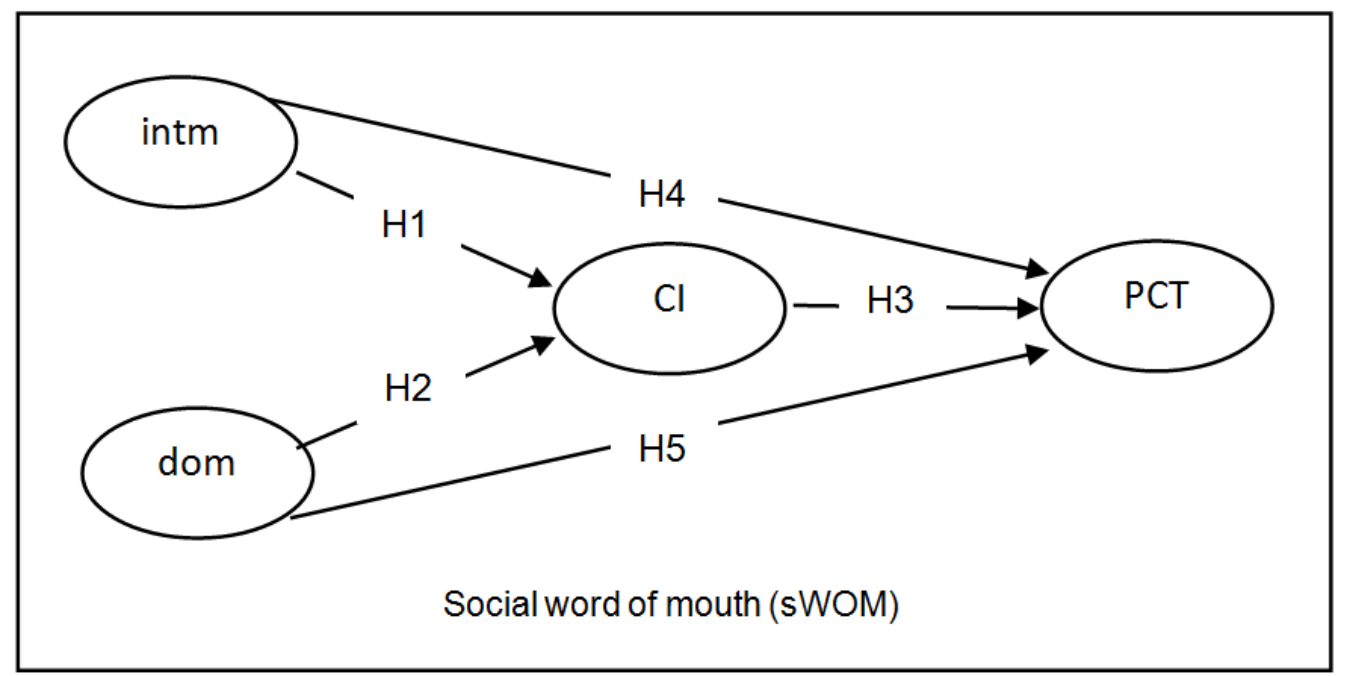

Figure 1 - Proposed construct model

Intimacy, dominance and product comment trust-ability. The characteristic of intimacy which trigger closeness feeling. Intimacy towards social media participants is thus perceived (Jiang, 2011). Once intimate relations are sensed, the immunity from the manipulation of the participating behavior of social media community members increases (Walther and Parks, 2002). Social media participation behaviors turn out to be easily inferred (Walther et al., 
2008). That is, social media community behaviors seem to become predictable and interpretable (Glen, 1979). So that, it supports to develop a further hypothesis as follow:

H4: The higher the perceived intimacy of social media community participants is, the higher the perceived product comments trust-ability will be.

In social media, the ubiquity of the Internet to jointly connect and link the public together and the self-disclosure character of Web 2.0 may form the impression of difficulty for individuals to manipulate others and override the public (Guerrero et al, 2013). Since the public also has better interpretations using various cues and thus easy to be accepted, it is, therefore, likely to signify that the public opinions are warranted more accurate. Hence, the dominance message which reflects provocative style will arouse trust-ability on product comment, this statement able to support the following hypothesis:

H5: The higher the perceived dominance of social media community participants is, the higher the perceived product comments trust-ability will be.

\section{RESEARCH METHODOLOGY}

The data were collected in Taiwan, thus a back translation technique was utilized to translate all scale items into the local official language, Chinese Mandarin. Two bilinguals were involved in the translation until no difference existed. The Mandarin version questionnaire was pilot-tested toward 11 university students. The data were collected in one national university and one private university with systematic sampling technique. By 500 questionnaires were distributed, while 470 were received and 408, including 201 and 207 from the national and private universities respectively, were identified useable for final data analysis.

The scales used in the current research were adopted from existing literature, which measured using a seven-point Likert scale. The research framework includes two precursors, including intimacy and dominance, were measured using Burgoon and Hale's (1987) seven-, and five-item scales. The measure of comment involvement was adapted from Zaichkowsky (1994) dual-dimensional scale which includes cognitive and affective and each dimension had five items (10 items in total). The outcome variables are product comments trust-ability was operationalized by adapting the three- scale of Hsiao et al. (2010). Also, the adopted related scales from Burgoon and Hale (1987), Walther (1990, p.109), Glen (1979), and Zaichkowsky (1994) have been frequently applied or modified in literature, such as Ramirez et al. (2007), Ramirez (2007), Walther and Burgoon (1992), Burgoon and La Poire (1999), Lowenthal and Dunlap (2010), Car and Walther (2014), Tidwell and Walther (2002), Racherla (2012), and Hanna and Shalom (2013). These scales, with good applicability evidenced in literature, were deemed suitable for the current research.

\section{DATA ANALYSIS AND RESULTS}

Sample characteristics. The respondents of the survey had some characteristics as described in Table 1. Among 408 participants, females were dominant with $53.7 \%$. The majority of respondent were adolescent aging less than or equal to 25 (i.e., $96.0 \%$ ). More than $90 \%$ of them had an average disposable income of less than 9, 000 NTD (New Taiwan Dollar). Regarding education levels, undergraduate students occupied the most, at $67.2 \%$, followed by post-graduates of $31.1 \%$ and the rest of $1.7 \%$ was doctorate students. With respect to the experience of using Facebook, a big portion of respondents $(69.6 \%)$ had used Facebook more than three years while more of them $(33.6 \%)$ spent from one to two hours per day for playing such social media.

Scale accuracy. The composite reliability (CR) and average variance extracted (AVE) of the studied dimensions and constructs were tested for reliability assessment. Then, the final results showed the CR values ranged from .754 to .948, all above the commonly suggested threshold of .7. With a marginally acceptable case of .48 which was retained for content validity concern, the other obtained AVEs were higher than the recommended value of .5 (see table 2). Both results demonstrated an acceptable and satisfactory reliability for all 
variables. For convergent validity assessment, three items of intimacy and three items of involvement which had a loading value to its corresponding dimension to be less than the stipulated threshold of .5 was removed. Then, all the remaining loading values exceeded the cut-off value. Therefore, every scale was of good convergent validity.

Table 1 - Sample characteristics

\begin{tabular}{|c|c|c|c|c|c|}
\hline Gender & Freq. & $\%$ & Education Background & Freq. & $\%$ \\
\hline Male & 189 & 46.3 & Undergraduates & 274 & 67.2 \\
\hline Female & 219 & 53.7 & Post-graduates & 127 & 31.1 \\
\hline Total & 408 & 100.0 & Doctorate students & 7 & 1.7 \\
\hline Age & Freq. & $\%$ & Total & 408 & 100.0 \\
\hline$\leq 20$ & 196 & 48.0 & Age of Facebook Users & Freq. & $\%$ \\
\hline $21-25$ & 196 & 48.0 & $\leq 1$ year & 11 & 2.7 \\
\hline $26-30$ & 13 & 3.2 & $<1-2$ years $\leq$ & 23 & 5.6 \\
\hline$>30$ & 3 & 0.7 & $<2-3$ years $\leq$ & 90 & 22.1 \\
\hline Total & 408 & 100.0 & $>3$ years & 284 & 69.6 \\
\hline Monthly disposable Income (NTD) ${ }^{*}$ & Freq. & $\%$ & Total & 408 & 100.0 \\
\hline$\leq \$ 6,000$ & 186 & 45.6 & Facebook Usage per Day & Freq. & $\%$ \\
\hline$<\$ 6,000-\$ 9,0000 \leq$ & 190 & 46.6 & $\leq 1$ hours & 103 & 25.2 \\
\hline$<\$ 9,000-\$ 12,000 \leq$ & 21 & 5.1 & $<1-2$ hours $\leq$ & 137 & 33.6 \\
\hline$>\$ 12,000$ & 11 & 2.7 & $<2-3$ hours $\leq$ & 92 & 22.5 \\
\hline Total & 408 & 100.0 & $>3$ hours & 76 & 18.6 \\
\hline New Taiwan Dollars; exchan & $=\$ 0$ & SD & Total & 408 & 100.0 \\
\hline
\end{tabular}

Table 2 - Scale accuracy analysis result

\begin{tabular}{|l|c|c|}
\hline \multicolumn{1}{|c|}{ Research construct } & AVE & Composite reliability \\
\hline Intimacy & 0.480 & 0.754 \\
\hline Dominance & 0.596 & 0.880 \\
\hline Comment involvement & 0.580 & 0.906 \\
\hline Product comment trust-ability & 0.860 & 0.948 \\
\hline
\end{tabular}

Structural model. A t-test calculated from the bootstrapping procedure of 500 samples was applied to examine the hypothesized effects, while Cohen's Indicator $\left(f^{2}\right)$ was used to measure the effect sizes of the studied relationships with the values of $.35, .15$, and .02 to signify large, medium, and small effects, respectively (Henseler et al., 2009).

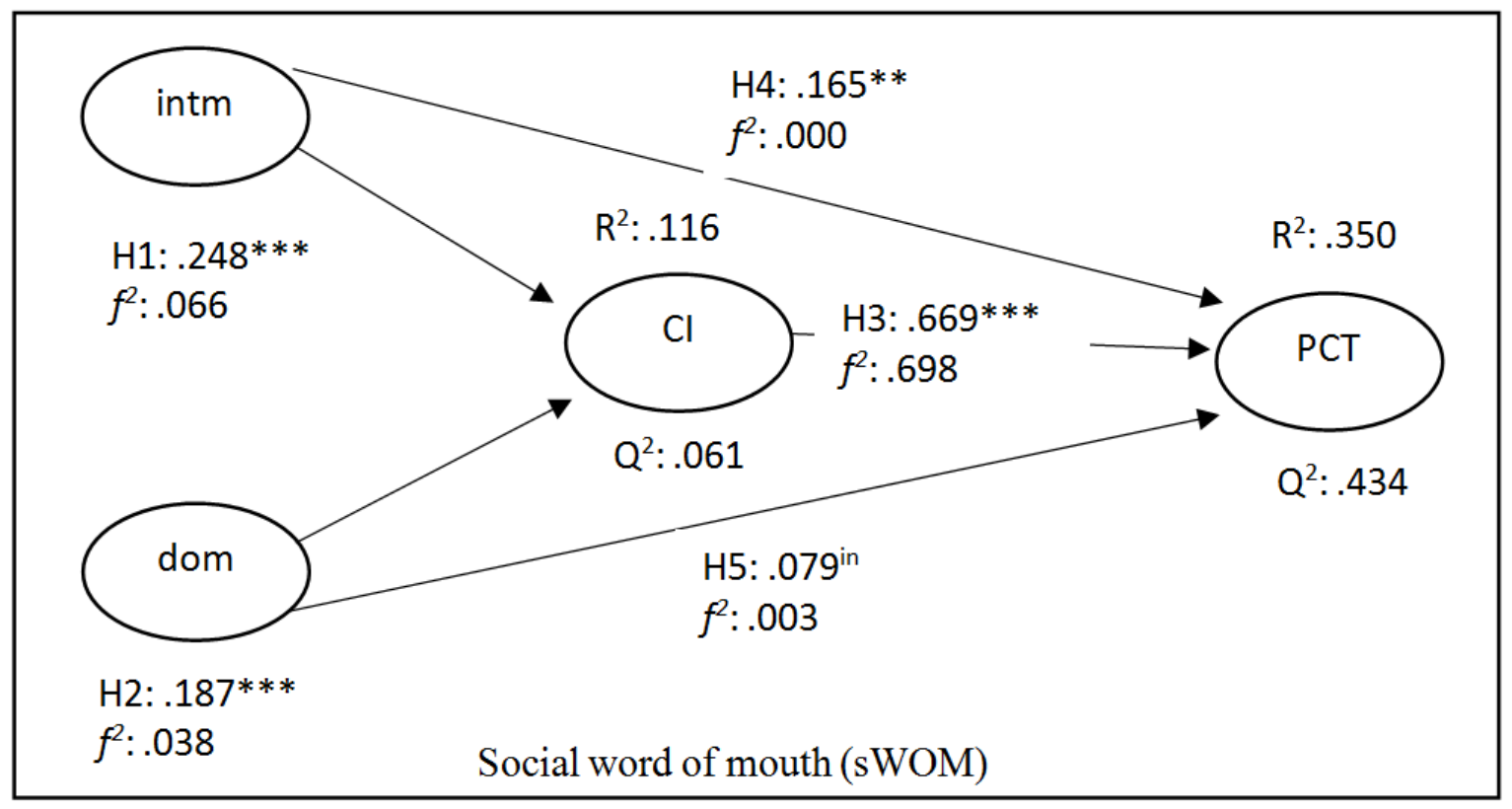

Notes: ${ }^{*} p<.05 ;{ }^{* *} p<.01 ;{ }^{* * *} p<.001$, in: insignificant.

Figure 2 - The result of main direct effect testing 
As showed in Figure 2, the t-test results revealed that four out of five direct hypotheses $(\mathrm{H} 1, \mathrm{H} 2, \mathrm{H} 3, \mathrm{H} 4)$ were supported, while the effects of dominance to PCT $(\mathrm{H} 4)$ is failed to support the hypothesis. Among the significant relationships, comment involvement exhibited a large effect size on product comments trust-ability, whereas the effect size of the other supported hypotheses ranged between medium to small levels.

For further analysis regarding mediating effect able to assess from main direct effect result. Following Baron and Kenny (1986) as long as the precursor significant toward the mediator, then the mediator significant toward the outcome, it able to conclude that any mediating relevancy. Therefore, for a case of the current study able to conclude that $\mathrm{Cl}$ success as the mediator between both of the precursor (intimacy and dominance). Since H5 failed to supported means $\mathrm{Cl}$ as the perfect mediator of the relationship between dominance and PCT. While $\mathrm{Cl}$ as the partial mediator between the relationships of intimacy toward PCT.

\section{DISCUSSION OF RESULTS}

The current research explores the precursors of product comment trust-ability in the sWOM context. Driven by the SIP theory as the principle scholarly ground, two precursors are introduced, including intimacy, and dominance which affect the trust-ability through the intervening factors of comment involvement. While the field study is conducted in Taiwan, there is one finding insignificant with anticipation. The current findings show, in a social media community, dominance does not affect the perceived trust-ability of product comment. It occurs, since dominance that reflects of the aggressiveness of message characteristics, sometimes make the person feel doubt with the content truth. If the message extreme dominance, it more likely fraudulence. In fact, dominance on social media shouldn't be extreme since the richness information on social media encourages the user to more selective when seeking the information (Shalom, 2015). By doing so, the variable dominance should involve the mediator of $\mathrm{Cl}$ to reach the PCT, it is called as the perfect mediating relevancies.

Research implication. Theoretically, the findings lend empirical evidence in Taiwan to the applicability of the SIP theoretical concept in the studied subject. The presences of mediating roles clarify the dynamics of the proposed framework for the linkages from the predicting antecedents to the outcome variable. Such a demonstrated theoretical mechanism provides critical insight into and broadens the body of the extant knowledge of sWOM product comments from the perspective of interactive and relational communication. However, since the prior applications of the SIP theory are mainly in developed Western cultures and Japan (e.g., Walther and Burgoon 1992; Farer and Gavin 2009; Lam and Mayer 2014) and the current research refers to a baseline as an initial verification of the SIP theory in sWOM, the occurrence of some unsupported hypothesized relationships may suggest to fine tune the SIP theory if applied around the globe and across sectors, in particular in various contemporary proliferated virtual environments. Caution should be paid for its theoretical applications in contingencies and diverse settings, rather than taking a generalized viewpoint for its application.

Practically among the information exchange precursors, intimacy is the most effective approach to boost up the perceptions of the trust-ability of product comment posted on social media communities. Strategies can thus be made such as to stimulate and encourage customers to interact with social media communities using a receptive and equal way through a closeness tone. A second strategic priority lies in the way of dominance during relational communication. More persuasive communicative fashions in an aggressive manner should be used, as such getting approval from social media community members. However, it should be mentioned that the ineffective without the role of comment involvement. Thus, besides using the dominance style, it should encourage the other involvement to reach the trust-ability of product comment on social media. Such a conclusion might infer that other types of social media such as YouTube, a content site specifically for video sharing, rather than Facebook, mainly for social relationship building, might be more suitable platforms for sWOM to product comment purpose. 


\section{CONCLUSION}

As previous studies, the current empirical research inherits several limitations from the nature of the research which provides fruitful and promising avenues for future research. The current research focuses on investigating the two studied relational communication factors as the antecedent precursors of subsequent outcomes. However, one studied mediating $R^{2}$ value is relatively weak in terms of its variance explanation. This might suggest further exploration of other antecedent variables, in particular, other relational communication variables such as relaxation and immediacy (see Burgoon and Hale (1987) for a more thorough review of these communication variables) as additional driving forces, as such increasing the variance explanation of research moderators. Another inherited limitation is that the field study is conducted in Taiwan in a Facebook context without considering specific product offerings.

Since introduced and as noted implicitly above, social media have proliferated (e.g., for social networking or content community purposes) and each type presents some unique characteristics and provides specific benefits to surfers (also see Bergh et al., 2011; Kaplan and Haenlein, 2010). For example, Facebook is a social networking site in which individuals share all types of content with others for networking and relationship-building/maintaining, while YouTube, a content community site, concentrates on specific content sharing and content searching. The unique characteristics in various social media proliferations exhibit different crucial implications in online social media communication and resultant conducts. Future research can seek to answer this call for duplicating the current research in other types of, rather than Facebook, social media contexts.

Furthermore, product types can affect purchase motivations and decisions (Yoon, 2013), and as a consequence, is likely to produce different impacts on the proposed relationships. It is thus worthwhile to observe and differentiate the results of the proposed hypotheses from various product category aspects. Last but not least, prior empirical studies indicate that the product comment trust-ability have an effect on purchase intention and actual shopping decisions (e.g., Hsiao et al., 2010; Xu and Yao, 2015). A more comprehensive conceptual framework incorporating these purchase conducts in the current study can be empirically tested, thus providing a more synthesized solution for drawing the communication-shopping hierarchical relationship in the social media environment.

\section{REFERENCES}

1. Augie R. 2014. What if everything you know about social media marketing is wrong? Available online http://www.experiencetheblog.com/2014/04/what-if_everything-youknow-about.html [Accessed 28 February 2016].

2. Baron RM, Kenny DA. 1986. The moderator-mediator variable distinction in social psychological research: conceptual, strategic, and statistical considerations. Journal of Personality and Social Psychology 51(6): 1173-1182.

3. Burgoon JK, Hale JL. 1987. Validation and measurement of the fundamental themes of relational communication. Communication Monograph 54(1): 19-41.

4. Carr CT, Walther JB. 2014. Increasing attributional certainty via social media: learning about others one bit at a time. Journal of Computer-Mediated Communication 19(4): 922-937

5. Cheung TMK, Thadani DR. 2010. The effectiveness of electronic word-of-mouth communication: a literature analysis. 23rd Bled eConference eTrust: Implications for the Individual, Enterprises and Society June 20 - 23, 2010, Bled, Slovenia.

6. Chow SS, Wing S. 2015. Trust development and transfer in social commerce: prior experience as moderator. Industrial Management \& Data Systems, 115(7): 1182-1203.

7. Chu SC. 2011. Viral advertising in social media: participation in Facebook groups and responses among college-aged users. Journal of Interactive Advertising 12(1): 30-43.

8. Farrer J, Gavin J. 2009. Online dating in japan: a test of social information processing theory. Cyberpsychology \& Behavior 12(4): 407-412. 
9. Glen WC. 1979. Attributional confidence and uncertainty in initial interaction. Human Communication Research 5(2): 147-157.

10. Guerrero, L.K., Andersen, P. A., \& Afifi, W. A. 2013. Close encounters: Communication

11. in relationships. Sage Publications: New York, USA: pages 20-22.

12. Hajli N, Lin X, Featherman M, Wang Y. 2013. Social word of mouth: how trust develops in the market. International Journal of Market Research 56(5): 673-689.

13. Hanna GG, Shalom L. 2013. Does consumers' personal involvement have an influence on store brand buying proneness?. The Journal of Consumer Marketing 30(7): 553-562.

14. Henseler J, Ringle CM, Sinkovics R. 2009. The use of partial least squares path modeling in international marketing. In Sinkovics RR, Ghauri PN (ed.), New Challenges to International Marketing: Advances in International Marketing, Vol. 20, Emerald Group Publishing Limited: Bingley, UK, pp. 277-319.

15. Hsiao KL, Lin JCC, Wang, XY, Lu HP, Yu HJ. 2010. Antecedents and consequences of trust in online product recommendations: an empirical study in social shopping. Online Information Review 34(6): 935-953.

16. Jeff B. 2015. 33 social media facts and statistics you should know in 2015. Available online http://www.jeffbullas.com/2015/04/08/ [Accessed 28 February 2016]

17. Jiang LC, Bazarova NN, Hancock JT. 2011. The disclosure-intimacy link in computermediated communication: an attributional extension of the hyperpersonal mode. Human Communication Research 37(1): 58-77.

18. Kaplan AM, Haenlein M. 2010. Users of the world, unite! The challenges and opportunities of social media. Business Horizons 53(1): 59-68.

19. Katrin, W. 2015. Accepting the challenges of social media research. Online Information Review 39(3): 281-289.

20. Lam CF, Mayer DM. 2014. When do employees speak up for their customers? A model of voice in a customer service context. Personel Psychology 67(3): 637-666

21. Lee D, Hosanagar K, Nair HS. 2014. The effect of social media marketing content on consumer engagement : evidence from Facebook. Social Science Research Network. Working paper, Tepper School of Business, Carnegie Mellon University, Pittsburgh.

22. Lowenthal PR, Dunlap JC. 2010. From pixel on a screen to real person in your students' lives: Establishing social presence using digital storytelling. Internet and Higher Education 13(1/2): 70-72

23. Michael AS. (2015). 2015 social media marketing industry report how marketers are using social media to grow their businesses. Available online SocialMediaExaminer.com [Accessed 28 February 2016]

24. $\mathrm{Ng} \mathrm{TWH}$, Feldman DC. 2013. Changes in perceived supervisor embeddedness: effects on employees' embeddedness, organizational trust, and voice behavior. Personnel Psychology 66(1): 645-685.

25. Park DH, Lee J. 2008. eWOM overload and its effect on consumer behavioral intention depending on consumer involvement. Electronic Commerce Research and Applications 7(4): 386-398.

26. Perez DG. 2009. Automatic nonverbal analysis of social interaction in small groups: a review. Image and Vision Computing 27(12): 1775-1787.

27. Racherla P, Mandviwalla M, Connolly D. 2012. Factors affecting consumers' trust in online Ramirez AJR, Shuangyue Z, Cat M, Lin SF. 2007. Relational communication in computer-mediated interaction revisited: a comparison of participant-observer perspectives. Communication Monographs 74(4): 492-516.

28. Tidwell LC, Walther JB. 2002. Computer-mediated communication effects on disclosure, impressions, and interpersonal evaluations getting to know one another a bit at a time. Human Communication Research 28(3): 317-348.

29. Utz, S. 2000 . Social information processing in MUDs: the development of friendships in virtual worlds. Journal of Online Behavior 1(1): 1-25.

30. Walther JB, Burgoon JK. 1992. Relational communication in computer-mediated interaction. Human Communication Research 19(1): 50-88.

31. Walther JB, Parks MR. 2002. Cues filtered out, cues filtered in: computer-mediated 
communication and relationships. In Mark LK and John AD (ed.). Handbook of Interpersonal Communication (3rd ed.). Sage: Thousand Oaks, CA, USA, pp. 529-563.

32. Walther JB. 1997. Group and interpersonal effects in international computer-mediated collaboration. Human Communication Research 23(3): 342-369.

33. Walther JB. 2008. Social information processing theory: impression and relationalship development online. In Leslie AB and Dawn OB (ed.). Engaging Theories in Interpersonal Communication: Multiple Perspective. Sage: New York, NY, USA, 391-427.

34. Walther JB. 2012. Social information processing theory. In Griffin EM (ed). A First Look at Communication Theory (8th ed.). McGraw-Hill: New York, NY, USA; 138-149.

35. Watanabe N, Yamamoto M. 2015. Neural mechanisms of social dominance. Journal Frontiers in Neuroscience 9(154): 1-14

36. Wei Shao RG, Jones DG. 2015. Brandscapes: contrasting corporate-generated versus consumer-generated media in the creation of brand meaning. Marketing Intelligence \& Planning 33(3): $414-443$

37. Xu X, Yao Z. 2015. Understanding the role of argument quality in the adoption of online reviews. Online Information Review 39(7): 885-902.

38. Yoon SJ. 2013. Antecedents and consequences of in-store experiences based on an experiential typology. European Journal of Marketing 47(5/6): 693-714.

39. Zaichkowsky JL. 1994. The personal involvement inventory: reduction, revision, and application to advertising. Journal of Advertising 23(4): 59-70

40. Zhiming L, Li H, Lu L. 2014. An investigation of online review helpfulness based on movie reviews. African Journal of Business Management 8(12): 441-450. 